\title{
Effects of Deposition and Annealing Temperature on the Structure and Optical Band Gap of $\mathrm{MoS}_{2}$ Films
}

\author{
Gongying Chen ${ }^{1}$, Benchu Lu ${ }^{1}$, Xinyu Cui ${ }^{1}$ and Jianrong Xiao ${ }^{1,2, * \mathbb{D}}$ \\ 1 College of Science, Guilin University of Technology, Guilin 541004, China; chengy1104@163.com (G.C.); \\ benchuul@163.com (B.L.); cuixinyu0210@163.com (X.C.) \\ 2 School of Physics and Electronics, Central South University, Changsha 410083, China \\ * Correspondence: xjr@glut.edu.cn
}

Received: 2 November 2020; Accepted: 30 November 2020; Published: 3 December 2020

\begin{abstract}
In this study, molybdenum disulfide $\left(\mathrm{MoS}_{2}\right)$ film samples were prepared at different temperatures and annealed through magnetron sputtering technology. The surface morphology, crystal structure, bonding structure, and optical properties of the samples were characterized and analyzed. The surface of the $\mathrm{MoS}_{2}$ films prepared by radio frequency magnetron sputtering is tightly coupled and well crystallized, the density of the films decreases, and their voids and grain size increase with the increase in deposition temperature. The higher the deposition temperature is, the more stable the $\mathrm{MoS}_{2}$ films deposited will be, and the $200{ }^{\circ} \mathrm{C}$ deposition temperature is an inflection point of the film stability. Annealing temperature affects the structure of the films, which is mainly related to sulfur and the growth mechanism of the films. Further research shows that the optical band gaps of the films deposited at different temperatures range from $0.92 \mathrm{eV}$ to $1.15 \mathrm{eV}$, showing semiconductor bandgap characteristics. The optical band gap of the films deposited at $200{ }^{\circ} \mathrm{C}$ is slightly reduced after annealing in the range of $0.71-0.91 \mathrm{eV}$. After annealing, the optical band gap of the films decreases because of the two exciton peaks generated by the K point in the Brillouin zone of $\mathrm{MoS}_{2}$. The blue shift of the $\mathrm{K}$ point in the Brillouin zone causes a certain change in the optical band gap of the films.
\end{abstract}

Keywords: molybdenum disulfide films; magnetron sputtering; deposition temperature; crystal structure; optical band gap

\section{Introduction}

Molybdenum disulfide $\left(\mathrm{MoS}_{2}\right)$ has a unique layered structure that is composed of S-Mo-S layers with covalent bonds and hexagonal coordination. Adjacent layers are formed by weak van der Waals forces $[1,2]$. $\mathrm{MoS}_{2}$ has many excellent properties and has been widely used in many fields, such as desulfurization $[3,4]$, low consumption film transistors [5,6], and solid lubricants $[7,8]$, because of its unique structure and is a 2D material with Dirac cone structure $[9,10] . \mathrm{MoS}_{2}$ film materials have excellent electrical and optical characteristics [11]. $\mathrm{MoS}_{2}$ film materials have a high carrier mobility, which is higher than that of organic silicon and amorphous silicon materials. The films are annealed or combined with other materials, such as silicon carbide crystals, thereby effectively improving their electrical properties [12-15]. The films have a direct band gap of $1.93 \mathrm{eV}$ and an indirect band gap of $1.2 \mathrm{eV}[16,17]$, and they are a promising photocatalyst [18]. Therefore, studying the structure and performance of $\mathrm{MoS}_{2}$ films is or great practical significance.

Many preparation methods are used for $\mathrm{MoS}_{2}$ film, such as the liquid phase peeling method, but it is difficult to control that the quantity and shape of the prepared $\mathrm{MoS}_{2}$ film $[19,20]$. Metal organic chemical vapor deposition can effectively prepare uniform and dense $\mathrm{MoS}_{2}$ films with high yield, but it requires high environmental conditions for preparation and the grain size is difficult to control $[19,21]$. 
Some researchers have used magnetron sputtering to prepare $\mathrm{MoS}_{2}$ films. This technology has good stability, high film forming purity, good uniformity and fast film formation speed [6,22-25], and magnetron sputtering has a large control range in terms of deposition temperature, substrate and kinetic energy of charged argon ions [5]. This is conducive to the preparation of films with various structures. However, the main disadvantage of magnetron sputtering is that vulcanization will lead to the growth of polycrystalline blocks, which makes it difficult to achieve single-layer film deposition $[20,26]$. Moreover, the film prepared by magnetron sputtering sometimes has the problem of high stress, but we can improve this problem by optimizing the experimental parameters and annealing. High-quality vertical structure and multiple active sites can be obtained through magnetron sputtering [27], and the $\mathrm{MoS}_{2}$ films have good photocatalytic performance [28,29]. A study found that the quality of the film can be improved with better catalytic performance after annealing and desulfurization $[4,22,30]$. At the same time, annealing has a great effect on improving the electrical properties of the films. After annealing, the $\mathrm{MoS}_{2}$ films have a Hall mobility of $4.40 \mathrm{~cm}^{2} / \mathrm{Vs}$ and a carrier concentration of $12.5 \times 1016 \mathrm{~cm}^{-3}$. After annealing, the hysteresis voltage of the films can be expanded from $8.0 \mathrm{~V}$ to $28.4 \mathrm{~V}$ [31,32]. Heterostructures, such as Ni-MoS 2 structure, can also be obtained through magnetron sputtering. These heterostructures have extremely fast optical response time, high cutoff frequency, high conductivity and high photocatalytic activity $[24,25,33]$. Few studies are conducted on changing the parameters in magnetron sputtering and studying the effects of the process parameters on the structure and optical properties of films.

In this work, magnetron sputtering technology was used to prepare $\mathrm{MoS}_{2}$ films at different deposition temperatures and annealed at different temperatures. The effects of deposition and annealing temperature on the crystal structure, surface morphology, and optical band gap of the $\mathrm{MoS}_{2}$ films were thoroughly studied.

\section{Materials and Methods}

$\mathrm{MoS}_{2}$ films were prepared on single crystal silicon (100) and quartz wafers using a JGP-450a magnetron sputtering equipment developed by Shenyang Scientific Instrument Co. (Shenyang, China), Ltd., Chinese Academy of Sciences. The silicon wafer or quartz wafer was immersed in an ethanol solution, washed with an ultrasonic cleaner for $15 \mathrm{~min}$, rinsed with deionized water, and dried in an oven. The vacuum chamber was evacuated to $5.0 \times 10^{-4} \mathrm{~Pa}$. Argon gas (Ar, purity $99.99 \%$ ) was introduced, and the Ar flow rate was stable at 30 standard cubic centimeters per minute (precisely controlled by a gas flow meter). The working air pressure was set to $1.0 \mathrm{~Pa}$, and the RF power was 200 W. During sputtering, we used $\mathrm{MoS}_{2}$ target (Beijing Jingmai Zhongke Material Technology Co., Ltd., Beijing, China, Purity: $99.99 \%$, Size: $60 \times 3 \mathrm{~mm}$, Tolerance: $\pm 0.1 \mathrm{~mm}$ ) and the deposition temperature was selected to be $50{ }^{\circ} \mathrm{C}, 100^{\circ} \mathrm{C}, 200^{\circ} \mathrm{C}$, and $300^{\circ} \mathrm{C}$. The deposition time was $15 \mathrm{~min}$ (on the silicon substrate) and $3 \mathrm{~min}$ (on the quartz substrate). The $\mathrm{MoS}_{2}$ films prepared on the silicon and quartz wafers were annealed at different temperatures of $400{ }^{\circ} \mathrm{C}, 600^{\circ} \mathrm{C}$, and $800{ }^{\circ} \mathrm{C}$. During annealing, argon gas (Ar, purity $99.99 \%$ ) was continuously introduced. After reaching the annealing temperature, heating continued for $1 \mathrm{~h}$ and then naturally dropped to room temperature.

A scanning electron microscope (SEM, JSF-2100, Hitachi, Tokyo, Japan) was used to observe the surface morphology of $\mathrm{MoS}_{2}$ films on the silicon wafer before and after annealing, and various element contents of the films were obtained using an energy-dispersive spectrometer (EDS, Hitachi, Tokyo, Japan). An X-ray photoelectron spectrometer (XPS, Escalab250Xi, Thermo Fisher Scientific, Waltham, MA, USA) was used to analyze the bonding of various components of the thin film on the silicon wafer. The films on the silicon wafer was tested with an X-ray diffractometer (XRD, model X'pert3 Powder, Panalytical, Almelo, The Netherlands), and the physical image composition of the film was analyzed. An ultraviolet-visible light spectrometer (UV-vis, UV-2700, Shimadzu, Tokyo, Japan) was used to test the light transmission performance of the $\mathrm{MoS}_{2}$ films on the quartz wafer before and after annealing. In accordance with the light transmittance of the $\mathrm{MoS}_{2}$ films, their optical band gap was calculated using the Tauc equation. 


\section{Results and Discussion}

\subsection{Structure Analysis of the $\mathrm{MoS}_{2}$ Films}

Figure 1a-d show the SEM surface morphology of the $\mathrm{MoS}_{2}$ films prepared at deposition temperatures of $50{ }^{\circ} \mathrm{C}, 100{ }^{\circ} \mathrm{C}, 200{ }^{\circ} \mathrm{C}$, and $300{ }^{\circ} \mathrm{C}$. Figure 1e shows a high-magnification SEM image of the films prepared at $300{ }^{\circ} \mathrm{C}$, and Figure $1 \mathrm{f}$ shows the thickness of the film prepared at $200{ }^{\circ} \mathrm{C}$ (the thickness of the films is approximately $560 \mathrm{~nm}$ ). The deposition temperature has a great influence on the surface morphology of the films. The $\mathrm{MoS}_{2}$ films deposited at $50{ }^{\circ} \mathrm{C}$ show a clear granular structure on the surface, as shown by the yellow circle in Figure 1a. The $\mathrm{MoS}_{2}$ films prepared under the conditions of $100{ }^{\circ} \mathrm{C}, 200{ }^{\circ} \mathrm{C}$, and $300{ }^{\circ} \mathrm{C}$ show a "stripe" crystalline distribution (as shown by the yellow circle in Figure 1e), and the structural characteristics become evident with the increase in temperature. This structure is commonly found in the magnetron sputtering of $\mathrm{MoS}_{2}$ films, which can be attributed to their anisotropy. The growth rate of $\mathrm{MoS}_{2}$ at the edge of the vertical structure is different from the growth rate of the substrate, resulting in this intersecting structure. The surface of the $\mathrm{MoS}_{2}$ film becomes increasingly smooth and loose with the increase in deposition temperature, and many "feet" appear on the "stripe" from the SEM with high-magnification. The number of "feet" and the size increase with the increase in deposition temperature. These "feet" are the exposed edge sites of the $\mathrm{MoS}_{2}$ film, and these sites play an important role in improving the chemical activity and electron conduction [34,35]. A similar situation is found in the literature. When the deposition temperature is low, a granular surface morphology is easy to deposit, which is consistent with the SEM images observed in the literature [31]. A vertically aligned $\mathrm{MoS}_{2}$ films is easy to form with the increase in temperature [36,37]. This structure is because the growth rate of the films perpendicular to the substrate direction is slow, and the growth rate in the edge direction is slightly faster than that in the substrate direction at low temperatures. Therefore, this "particle" arrangement will appear on the film surface when the deposition temperature is low. The growth rate in the substrate direction increases, and the growth rate in the edge direction is relatively low when the temperature is high. Therefore, this dendritic structure will be formed on the film surface when the deposition temperature is high. The denser the surface of the films, the higher the deposition temperature and the looser they are when the surface structure of the films is "striped." On this basis, the boundary point of the deposition temperature of the film surface morphology is $200{ }^{\circ} \mathrm{C}$.

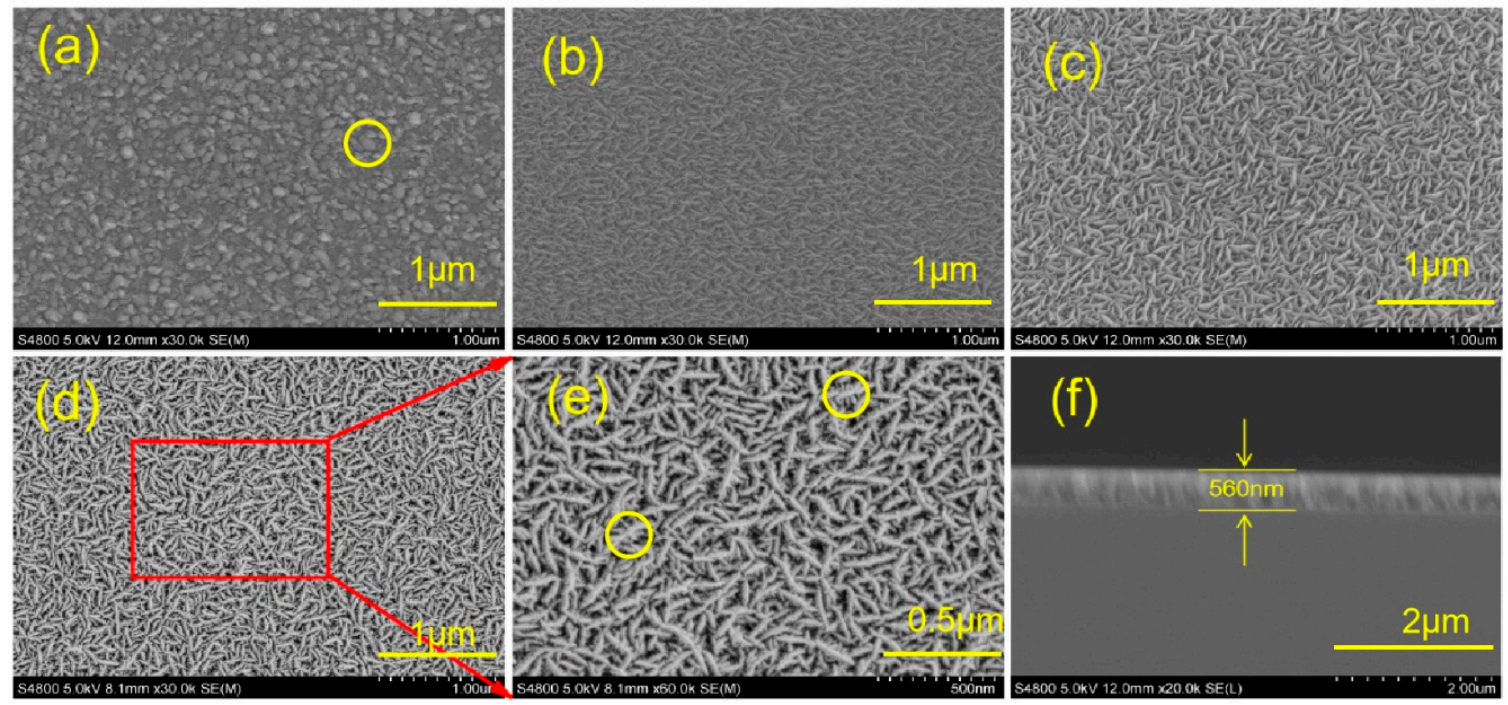

Figure 1. Scanning electron microscope (SEM) images of the $\mathrm{MoS}_{2}$ films prepared at different deposition temperatures: (a) $50{ }^{\circ} \mathrm{C}$, (b) $100{ }^{\circ} \mathrm{C}$, (c) $200{ }^{\circ} \mathrm{C}$, (d) $300{ }^{\circ} \mathrm{C}$, (e) high magnification, (f) cross section. 
Figure 2 shows the SEM morphology of $\mathrm{MoS}_{2}$ films prepared at different deposition temperatures and subjected to different annealing temperatures. Figure $2 \mathrm{a}-\mathrm{d}$ show the SEM images of the films annealed at $400{ }^{\circ} \mathrm{C}$ at different deposition temperatures. The films deposited at $50{ }^{\circ} \mathrm{C}$ and $100{ }^{\circ} \mathrm{C}$ showed a dense and smooth sheet structure after annealing at $400{ }^{\circ} \mathrm{C}$. However, a large amount of filamentous structures appeared on the surface of the films deposited at $200{ }^{\circ} \mathrm{C}$ and $300{ }^{\circ} \mathrm{C}$ after annealing at $400^{\circ} \mathrm{C}$. The appearance of this filamentous structure may be caused by the migration of $\mathrm{S}$ in the $\mathrm{MoS}_{2}$ crystal during annealing. Therefore, the evident characteristics of the layered structure are retained, as shown in Figure 2c,d. Figure 2e-h show the SEM images of the films prepared at different deposition temperatures after annealing at $400{ }^{\circ} \mathrm{C}$. The surface morphology of the annealed films in Figure $2 \mathrm{e}-\mathrm{g}$ completely changes at $400{ }^{\circ} \mathrm{C}$, and an evident layered structure is retained in Figure $2 \mathrm{~h}$. Annealing has a great influence on the $\mathrm{MoS}_{2}$ films and is affected by the deposition temperature. The surface structure of the film undergoes tremendous changes. This condition may be because of the difference in the mechanism of sulfur diffusion and the formation of $\mathrm{MoS}_{2}$ before and after annealing, thereby leading to changes in the morphology of the films. At the same time, high-temperature annealing can effectively improve the atomic mobility of the films, thereby allowing the atoms to be located in their energy matching position and improving the stability of the films [31]. Comparing the figures in Figure 2, the deposition temperature of $200{ }^{\circ} \mathrm{C}$ is the turning point of the surface structure of the films. The films prepared at $200{ }^{\circ} \mathrm{C}$ retain a good layered structure after annealing at $400{ }^{\circ} \mathrm{C}$. The layered structure is also preserved at $300{ }^{\circ} \mathrm{C}$, and the surface morphology of Figure $2 \mathrm{a}, \mathrm{b}$ below the preparation temperature of $200{ }^{\circ} \mathrm{C}$ completely changes from that before annealing. Therefore, the films prepared at a deposition temperature of $200^{\circ} \mathrm{C}$ have better stability, and the stability of the films is positively correlated with the deposition temperature, as shown in the comparison of the SEM images in Figure 2.
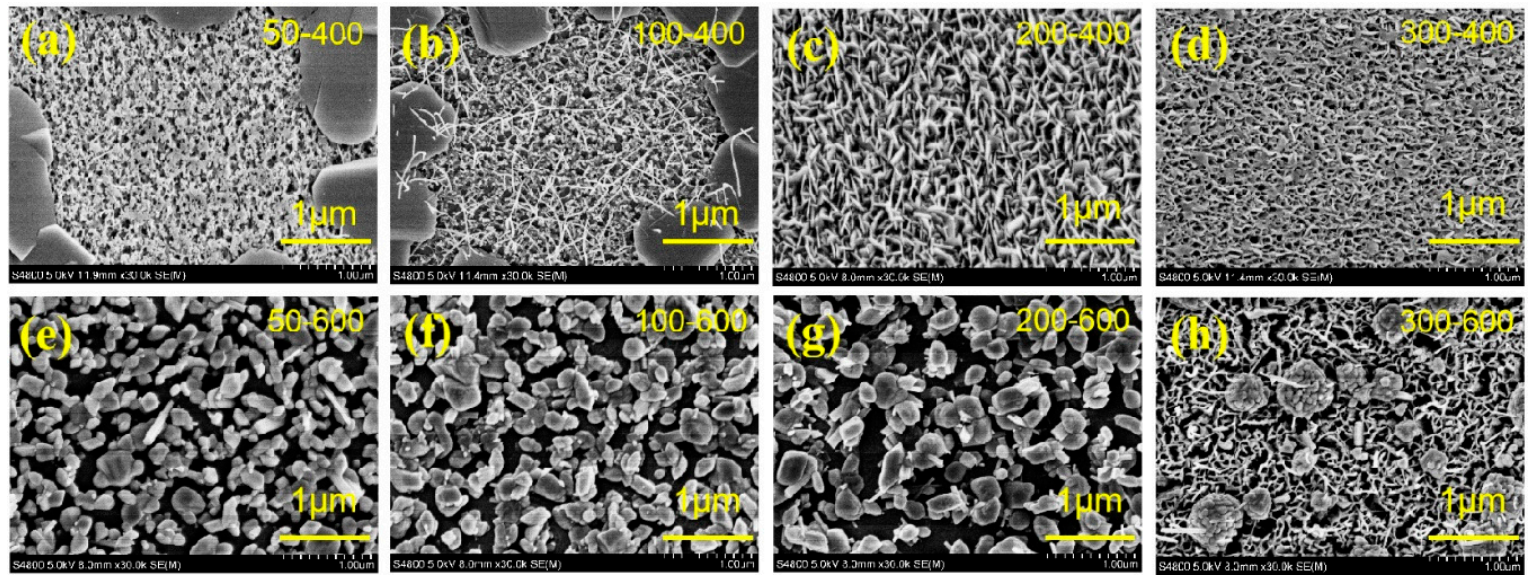

Figure 2. SEM surface morphology of the $\mathrm{MoS}_{2}$ films at different deposition-annealing temperatures: (a) $50-400^{\circ} \mathrm{C}$, (b) $100-400{ }^{\circ} \mathrm{C}$, (c) $200-400{ }^{\circ} \mathrm{C}$, (d) $300-400{ }^{\circ} \mathrm{C}$, (e) $50-600{ }^{\circ} \mathrm{C}$, (f) $100-600{ }^{\circ} \mathrm{C},(\mathrm{g}) 200-600{ }^{\circ} \mathrm{C}$, (h) $300-600{ }^{\circ} \mathrm{C}$.

Figure 3 shows the EDS spectrum of the $\mathrm{MoS}_{2}$ films prepared at different deposition temperatures, and the insets show the contents of the corresponding elements. In accordance with the EDS data, the elemental ratios of $\mathrm{S}$ and $\mathrm{Mo}$ in the films are 1.86:1, 1.62:1, 1.55:1, and 1.18:1 at $50{ }^{\circ} \mathrm{C}, 100{ }^{\circ} \mathrm{C}$, $200{ }^{\circ} \mathrm{C}$, and $300{ }^{\circ} \mathrm{C}$, respectively. The chemical ratio of molybdenum and sulfur in the actual films gradually decreases compared with the target chemical ratio with the increase in deposition temperature. This condition shows that the plasma energy increases with the increase in temperature, thereby destroying the S-Mo-S structure and forming a non- $\mathrm{MoS}_{2}$ chemical ratio structure. In Figure 3, a strong silicon element peak and an oxygen element peak appear. The silicon is attributed to the substrate single crystal silicon, and the oxygen element comes from the background atmosphere of the vacuum chamber. 


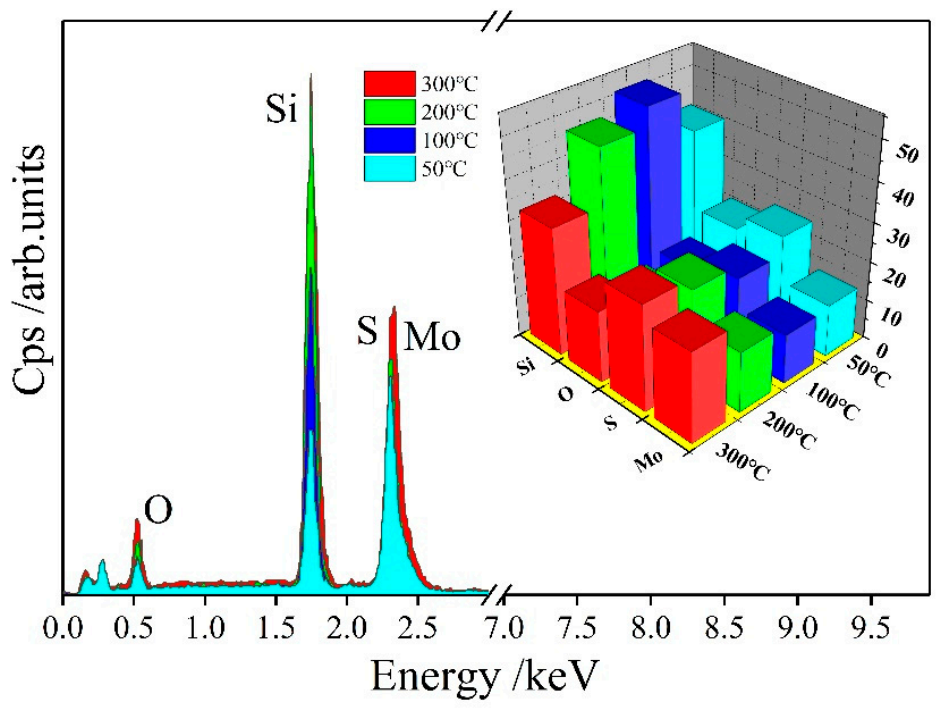

Figure 3. Energy-dispersive spectrometer (EDS) spectra of the $\mathrm{MoS}_{2}$ films prepared at different deposition temperatures.

Figure 4 shows the XRD pattern of $\mathrm{MoS}_{2}$ films prepared at different deposition temperatures. As shown in Figure 4a, each deposition temperature has a sharp peak at $62^{\circ}$ corresponding to $\mathrm{MoS}_{2}$ (107), and a relatively weak peak corresponds to $\mathrm{MoS}_{2}$ (100) when the deposition temperature is higher than $50^{\circ}$ at $33.3^{\circ}$. As shown in Figure $4 \mathrm{~b}$, two sharp peaks appear at $69.4^{\circ}$ and $69.6^{\circ}$ corresponding to $\mathrm{MoS}_{2}$ (202) and Si (100), respectively, the $33.3^{\circ}$ peak corresponds to $\mathrm{MoS}_{2}(100)$, and the $61.9^{\circ}$ peak corresponds to the $\mathrm{MoS}_{2}$ (107) plane, it is consistent with the XRD data in the literature [6,31,38]. Combined with the SEM results, the films are granular when the deposition temperature is low, and the growth rate is fast around this time. Thus, the crystallinity of the $\mathrm{MoS}_{2}$ (107) and $\mathrm{MoS}_{2}$ (202) surfaces is high. as the deposition temperature increases. The number of "feet" of the films gradually increases with the increase in deposition temperature when the film structure is "striped" to form a network structure. In particular, the number of "feet" is the largest at the temperature of $300{ }^{\circ} \mathrm{C}$. Thus, the (107) and (202) faces of $\mathrm{MoS}_{2}$ have the highest crystallinity compared with $100^{\circ} \mathrm{C}$ and $200^{\circ} \mathrm{C}$. This finding shows that the high deposition temperature in the "stripe" structure is beneficial to the growth of the lateral structure of the films. The $\mathrm{MoS}_{2}$ (100) surface only appears when the deposition temperature is high, which may be related to the growth of the films perpendicular to the substrate when the deposition temperature is high. These findings are in accordance with the SEM analysis of the $\mathrm{MoS}_{2}$ film surface structure changes with the deposition temperature.
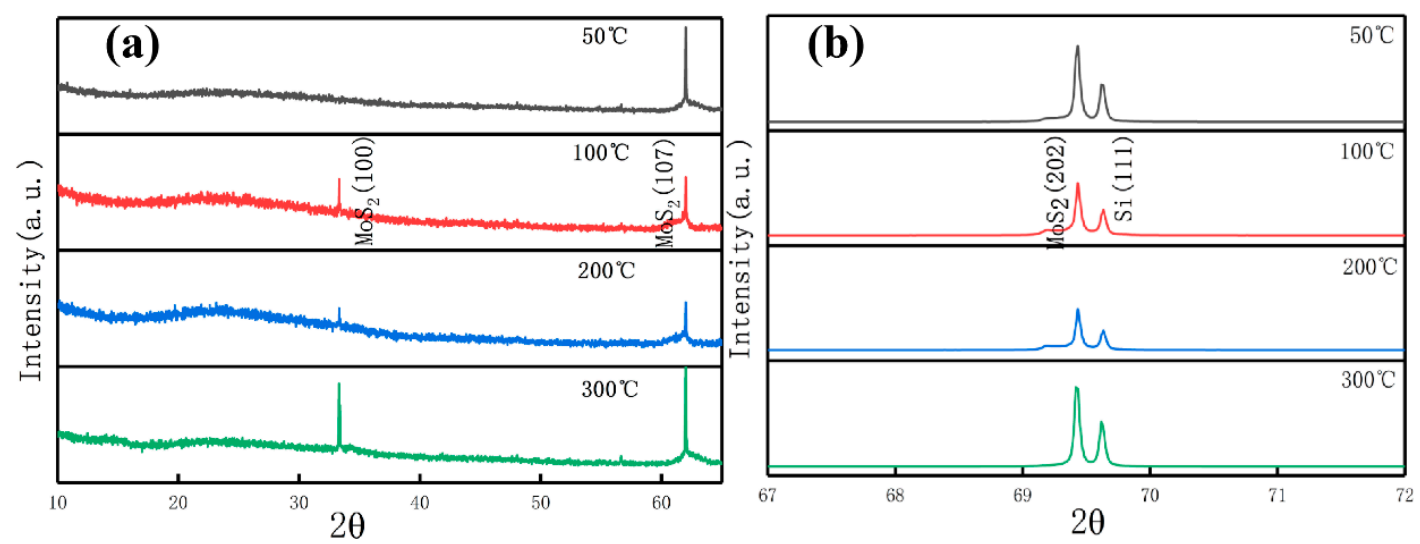

Figure 4. X-ray diffraction (XRD) patterns of the $\mathrm{MoS}_{2}$ films prepared at different deposition temperatures. Different diffraction angle range: (a) $2 \theta=10^{\circ} \sim 65^{\circ}$, (b) $2 \theta=67^{\circ} \sim 72^{\circ}$. (Picture a and $\mathrm{b}$ are continuous, and picture a is magnified). 
Figure 5 shows the XRD pattern of the $\mathrm{MoS}_{2}$ films prepared at $200{ }^{\circ} \mathrm{C}$ then annealing at $400{ }^{\circ} \mathrm{C}$, $600{ }^{\circ} \mathrm{C}$, and $800{ }^{\circ} \mathrm{C}$. As shown in Figure $5 \mathrm{~b}$, a strong peak appears at $62^{\circ} \mathrm{C}$ after annealing for the $\mathrm{MoS}_{2}$ (107) plane, and the peak is more intense than before annealing. The peak value intensively changes with the change in annealing temperature. Figure 5a shows the small peaks of $\mathrm{Mo}$ and $\mathrm{MoO}_{3}$ [39]. This condition is because annealing desulfurization occurs after annealing, resulting in a small portion of $\mathrm{MoO}_{3}$ and Mo crystals. In accordance with the XRD spectrum, the grain size of the $\mathrm{MoS}_{2}$ films can be calculated using the Scherrer formula. The calculated results are shown in Figure 6. For the change in the grain size of the thin films at different deposition temperatures, the average grain size of the $\mathrm{MoS}_{2}$ films with a granular structure is larger than the average size of the "stripe" structure. This condition shows that the growth modes of the two different film structures are completely different. The film grain size of the "stripe"-like structure regularly increases, indicating that the higher the deposition temperature, the better the crystallization of the "stripe"-like film structure. In accordance with the film deposited at $200^{\circ} \mathrm{C}$, the grain size of the films with different annealing temperatures can be clearly observed with the rapid decrease in grain size and increase in annealing temperature, and the change rule of the grain size is in line with the phenomenon observed in Figure 2 that the surface morphology of the annealed film becomes loose as the annealing temperature increases. The films deposited at $200{ }^{\circ} \mathrm{C}$ have a large increase in grain size before and after annealing at $400{ }^{\circ} \mathrm{C}$, indicating that a low annealing temperature is beneficial to the crystallization of the films. The films deposited at $200^{\circ} \mathrm{C}$ are annealed at $600{ }^{\circ} \mathrm{C}$ or $800^{\circ} \mathrm{C}$, and the grain size is immensely reduced, thereby increasing the grain boundary area. This condition reduces the physical and chemical properties of the films, increases their impurities, and increases the film's hardness and plastic toughness [40].
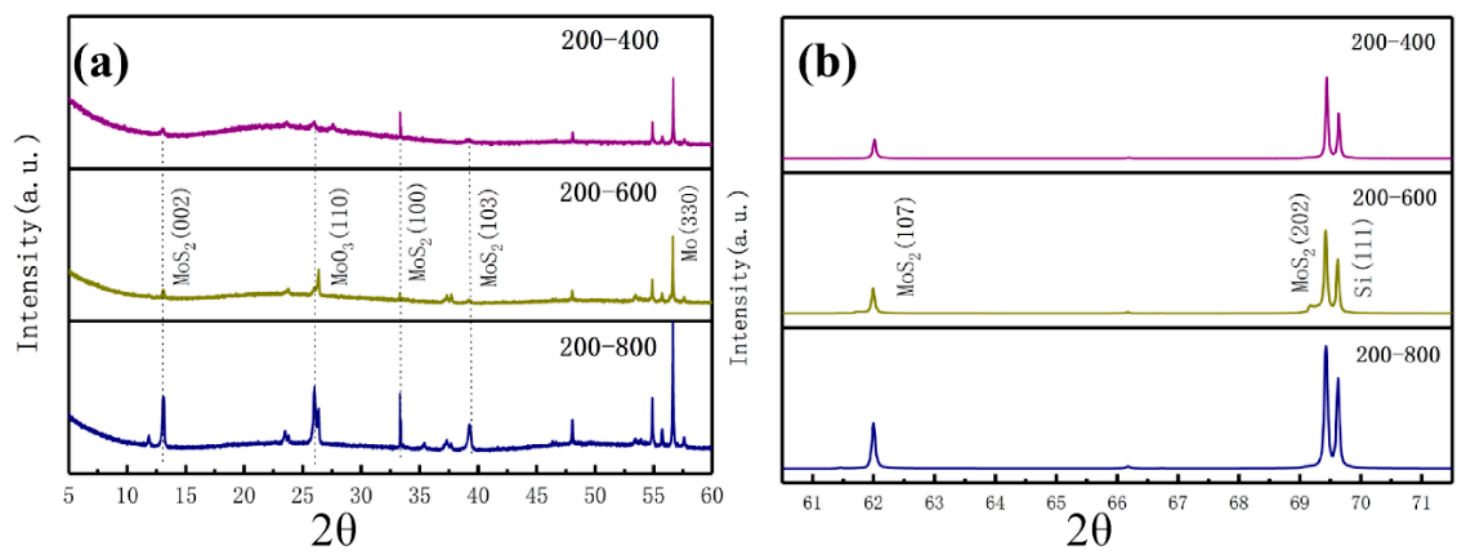

Figure 5. XRD spectrum of the $\mathrm{MoS}_{2}$ films prepared at $200{ }^{\circ} \mathrm{C}$ after annealing at $400{ }^{\circ} \mathrm{C}, 600{ }^{\circ} \mathrm{C}$, and $800^{\circ} \mathrm{C}$. Different diffraction angle range: (a) $2 \theta=5^{\circ} \sim 60^{\circ}$, (b) $2 \theta=60.5^{\circ} \sim 71.5^{\circ}$. (Picture a and $\mathrm{b}$ are continuous, and picture a is magnified) 


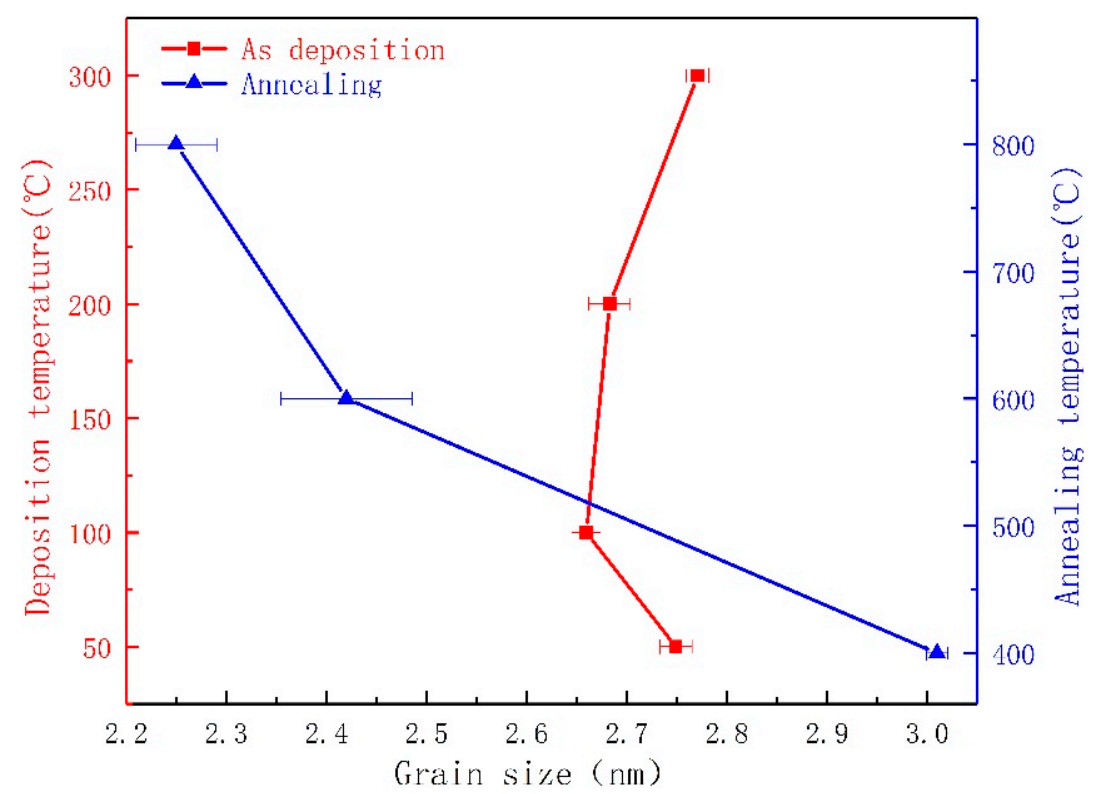

Figure 6. Relationship between the grain size of the $\mathrm{MoS}_{2}$ films and the deposition and annealing temperatures.

The XPS spectra of the $\mathrm{MoS}_{2}$ films prepared at $200{ }^{\circ} \mathrm{C}$ without annealing and $600{ }^{\circ} \mathrm{C}$ annealing are shown in Figure 7. In the deposition full spectrum, the binding energy of 230.0 and $161.5 \mathrm{eV}$ correspond to Mo3d and S2p, respectively, as shown in Figure 7a. Two weak peaks are easily found at 35.0 and $37.0 \mathrm{eV}$, indicating the existence of the Mo4p valence state in the films. In the full spectrum after annealing at $600{ }^{\circ} \mathrm{C}$, the S2p peak at $161.5 \mathrm{eV}$ disappears, and a weak peak appears at $155 \mathrm{eV}$. The sharp O1s peak appears in the figure, and the Si2p peak appears at the binding energy of $106 \mathrm{eV}$. This condition shows that high-temperature annealing has a great influence on the valence of elements in the films. To analyze the chemical composition of the $\mathrm{MoS}_{2}$ films in depth, Lorentzian fitting was performed on the peaks in each of the two full spectra. The Mo3d peak before annealing can be fitted into two peaks, as shown in Figure 7a. The binding energy of 228.5 and $231.4 \mathrm{eV}$ correspond to $\operatorname{Mo}_{5 / 2}$ and Mo3d $\mathrm{d}_{3 / 2}$, respectively [41,42]. The presence of peaks at 232.1 and $234.8 \mathrm{eV}$ can determine the presence of $\mathrm{Mo}^{6+}$ and indicate the presence of $\mathrm{MoO}_{3}$ in the film [41]. However, the peak area of $\mathrm{Mo}^{6+}$ is smaller than other peak areas, indicating that the main component of the films is still $\mathrm{MoS}_{2}$. The annealed Mo3d can still fit into a double peak, and the area of the Mo3d $\mathrm{d}_{5 / 2}$ peak is immensely reduced. The $\mathrm{MoO}_{x}$ peak significantly increases. This condition shows that free molybdenum ions increase and the high temperature activates the oxygen on the film surface after high-temperature desulfurization. Therefore, the two react to form molybdenum oxide. The grain boundaries in the annealed grain size enlarge, and the film impurities increase. After annealing, the binding energy of each peak shifts in parallel and moves by $1.0 \mathrm{eV}$ to the low-energy direction, making the structure of the films stable. The S2p high-resolution spectrum and fitting are shown in Figure $7 \mathrm{~b}$. Before annealing, the $S 2 p_{3 / 2}$ and $S 2 p_{1 / 2}$ peaks of the film are at the binding energy of 161.1 and $162.3 \mathrm{eV}$, respectively, thereby determining the presence of $\mathrm{S}^{2-}$ in the $\mathrm{MoS}_{2}$ films $[43,44]$. After high-temperature annealing, the $S 2 p_{3 / 2}$ and $S 2 p_{1 / 2}$ peaks immensely shift toward the binding, reducing the binding energy and making the structure stable. High-temperature desulfurization will improve the synthesis of $\mathrm{MoS}_{2}$ [45]. Figure 7c shows the high-resolution spectrum of $\mathrm{O} 1 \mathrm{~s}$ and the comparison between the two after fitting. The oxygen peak is activated under high-temperature conditions and produces many $\mathrm{MoO}_{2}$ impurities. Before and after annealing, the $\mathrm{Si}-\mathrm{O}$ bonds with oxygen peaks at 531.58 and $533.9 \mathrm{eV}$ originate from the $\mathrm{SiO}_{2}$ photoelectrons of the substrate [46]. 

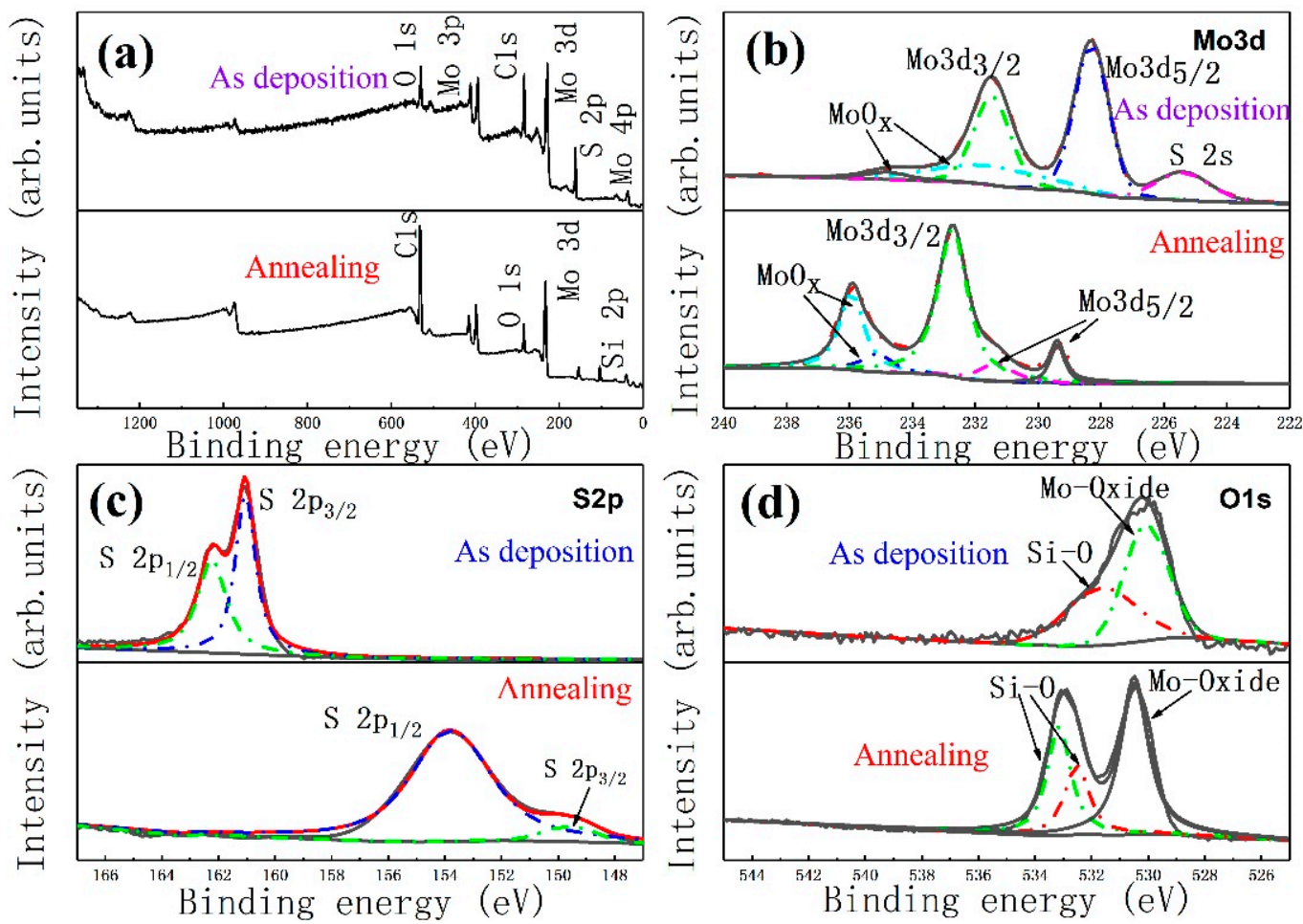

Figure 7. X-ray photoelectron spectrometer (XPS) pattern and Lorentzian fitting of each peak of the films deposited at $200{ }^{\circ} \mathrm{C}$ and the $\mathrm{MoS}_{2}$ films annealed at $200-600{ }^{\circ} \mathrm{C}$. (a) total spectrum, (b) Mo3d, (c) S2p, (d) O1s.

\subsection{Optical Band Gap of $\mathrm{MoS}_{2}$ Films}

The transmission spectra of $\mathrm{MoS}_{2}$ films prepared at different deposition temperatures in a quartz substrate are shown in Figure 8a. In accordance with the transmission spectrum of Figure 8a combined with the SEM and XRD analyses of the $\mathrm{MoS}_{2}$ films, the film with high crystallinity has better transmittance. From the transmission curves of $100{ }^{\circ} \mathrm{C}, 200{ }^{\circ} \mathrm{C}$, and $300{ }^{\circ} \mathrm{C}$, the deposition temperature has a great influence on the film with "stripe" structure. Figure $8 \mathrm{c}$ shows the transmission spectrum of $\mathrm{MoS}_{2}$ films deposited at $200^{\circ} \mathrm{C}$ with annealing at $400^{\circ} \mathrm{C}, 600{ }^{\circ} \mathrm{C}$, and $800{ }^{\circ} \mathrm{C}$. As shown in Figure $2 \mathrm{c}$, the surface structure of the films annealed at $200-400^{\circ} \mathrm{C}$ is similar to that before annealing (see Figure 1c). The transmission curve is similar to the transmission curve before annealing but the transmission rate is reduced. The surface morphology of the films after annealing at $200-600{ }^{\circ} \mathrm{C}$ completely changes, resulting in an abrupt transmission curve. They are B and A exciton peaks at $200 \mathrm{~nm}$ to $350 \mathrm{~nm}$ and $650 \mathrm{~nm}$ to $850 \mathrm{~nm}$, respectively. The two peaks are the transition regions of A and $\mathrm{B}$ excitons in the Brillouin zone and are caused by the blue shift of the $\mathrm{K}$ point in the Brillouin zone $[16,47,48]$. Therefore, a strong transmission peak appears at $400 \mathrm{~nm}$ to $650 \mathrm{~nm}$. The spectral transmittance significantly increases with the increase in annealing temperature. This condition may be attributed to two reasons: First, the increase in annealing temperature will cause the spectral absorption rate of $\mathrm{A}$ and $\mathrm{B}$ excitons to decrease. Figure $8 \mathrm{c}$ shows that the annealing temperature will affect the $\mathrm{K}$ point in the Brillouin zone of $\mathrm{MoS}_{2}$. Second, annealing desulfurization changes the surface morphology and crystal structure of the film, resulting in a drop in its optical properties. 

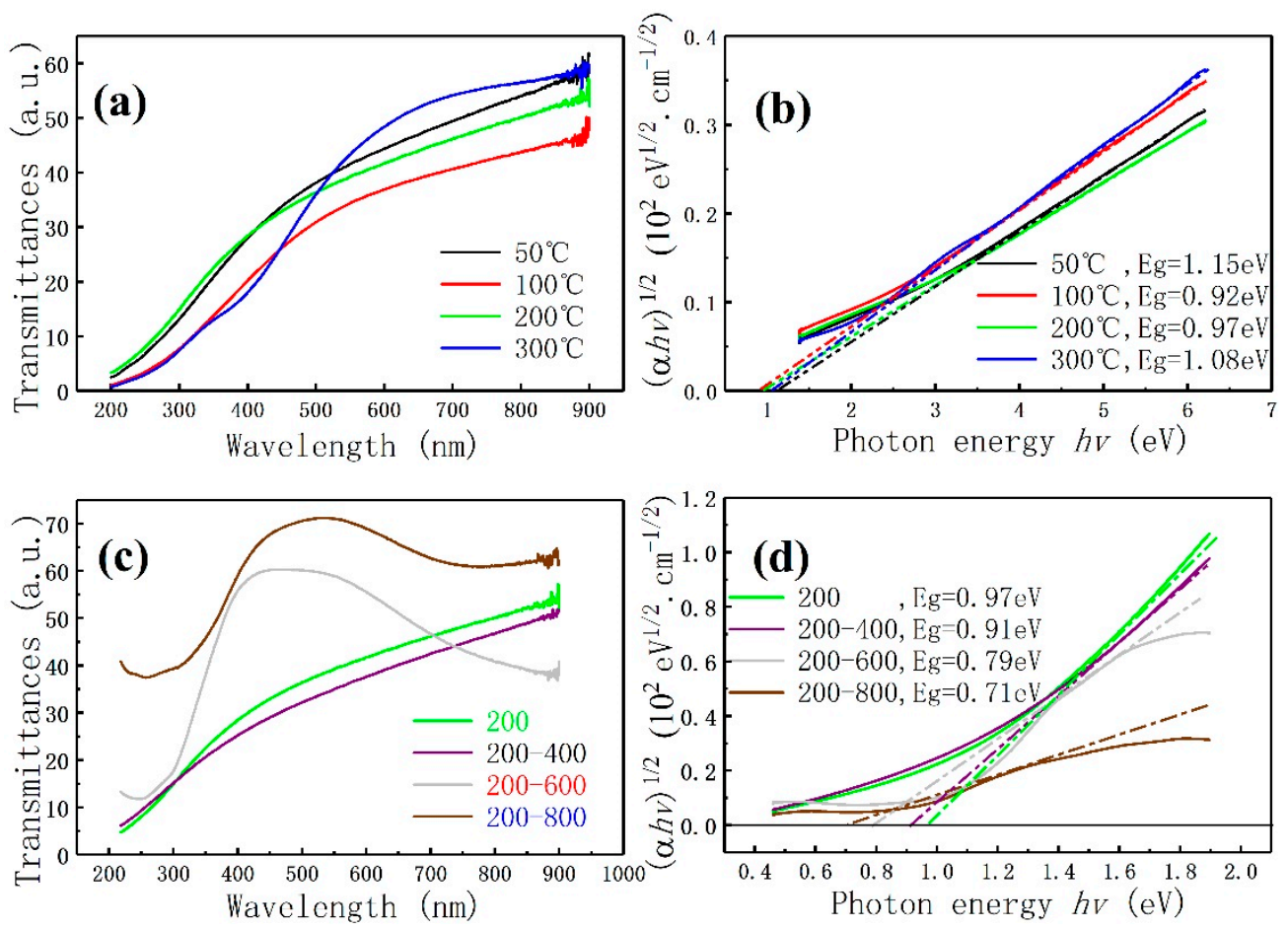

Figure 8. $\mathrm{MoS}_{2}$ films prepared at different deposition temperatures: (a) visible light transmittance, (b) the determination of the optical band gap. $\mathrm{MoS}_{2}$ films prepared at $200{ }^{\circ} \mathrm{C}$ annealing at different temperature: (c) visible light transmittance, $(\mathbf{d})$ determination of optical band gap.

Combined with the transmission spectrum of the film, the optical band gap of the film can be calculated using the Tauc equation [49,50]:

$$
\begin{gathered}
\alpha=\frac{\ln (100 / T)}{d} \\
(\alpha \mathrm{hv})^{1 / \mathrm{n}}=\mathrm{A}\left(\mathrm{hv}-\mathrm{E}_{\mathrm{g}}\right)
\end{gathered}
$$

where $\alpha$ is the absorption coefficient, $\mathrm{d}$ is the film thickness, $\mathrm{T}$ is the transmittance, and $\mathrm{A}$ is a constant. $\mathrm{n}$ is determined by the specific situation of direct or indirect band gap, which is 0.5 or 2 [49]. The relationship between $(\alpha h v)^{1 / 2}$ and $h v$ is calculated in accordance with the Tauc equation, and the tangent of the curve is obtained. The intersection of the tangent and the $\mathrm{X}$ axis is the optical band gap of the films. Figure $8 \mathrm{~b}$ shows the optical band gap energy of $\mathrm{MoS}_{2}$ films at different deposition temperatures. Figure $8 \mathrm{~d}$ shows the optical band gap of the $\mathrm{MoS}_{2}$ films prepared at $200{ }^{\circ} \mathrm{C}$ after annealing at different temperatures. Compared with the theoretical value $(1.29 \mathrm{eV})$ in the literature [17], the band gap energy of films prepared at different deposition temperatures is reduced by $0.14-0.21 \mathrm{eV}$; the optical band gap energy of $\mathrm{MoS}_{2}$ films prepared at $200^{\circ} \mathrm{C}$ is reduced by $0.32-0.58 \mathrm{eV}$. The deposition temperature and annealing treatment have a great influence on the band gap of the film. Combined with the SEM results, the optical band gap of the granular structure films is larger than that of the "stripe" structure, and the optical band gap of the "stripe" films is gradually widened with the increase in deposition temperature. Combined with the XRD analysis, the laterally grown crystal structure is beneficial to increase the band gap of the $\mathrm{MoS}_{2}$ films. Combined with the annealing temperature, the temperature has different effects on the growth mechanism of the $\mathrm{MoS}_{2}$ films, and that the films with granular and "stripe" structures are essentially different. Figure $8 \mathrm{~d}$ shows that annealing has a great effect on the optical band gap of the $\mathrm{MoS}_{2}$ films. After annealing at $400^{\circ} \mathrm{C}$, the indirect optical band gap of the films is reduced by $0.06 \mathrm{eV}$ compared with the as deposition films at $200^{\circ} \mathrm{C}$. The optical band gap changes slightly, indicating that the films change slightly. The band gaps of the films after 
annealing at $600{ }^{\circ} \mathrm{C}$ and $800{ }^{\circ} \mathrm{C}$ are 0.79 and $0.71 \mathrm{eV}$, respectively, indicating that high temperature annealing desulfurization will cause the crystal grain boundary to enlarge and affect the size of the optical band gap and the Brillouin zone. The $\mathrm{K}$ point has a great influence on the optical properties of the annealed $\mathrm{MoS}_{2}$ films.

\section{Conclusions}

At different deposition temperatures, the $\mathrm{MoS}_{2}$ film samples were prepared through magnetron sputtering and annealed. The results show that the surface of the thin film samples prepared by magnetron sputtering is flat and dense, with good quality and high crystallinity. The $\mathrm{MoS}_{2}$ films prepared at different deposition temperatures have different thermal stabilities. The higher the deposition temperature is, the better the thermal stability will be, and annealing desulfurization will occur. The suitable deposition temperature condition for preparing the $\mathrm{MoS}_{2}$ films is $200{ }^{\circ} \mathrm{C}$. The deposition temperature has a great influence on the film growth mechanism, which is reflected in the change in surface morphology and crystal structure. The surface structure of the films changes from granular to vertically arranged "stripe" structure with the increase in deposition temperature. The density of the vertically aligned structure becomes loose with the increase in temperature, and the ratio of $\mathrm{S}$ and Mo decreases. The high deposition temperature is conducive to the lateral growth of the films. A part of $\mathrm{Mo}^{6+}$ is generated in the films when the deposition temperature is $200{ }^{\circ} \mathrm{C}$, thereby forming $\mathrm{MoO}_{3}$ impurities and changing the composition and structure of the films. After annealing, the films have a tendency to agglomerate, and the lower the deposition temperature in the vertically aligned structure, the greater the strength of the film agglomeration will be. After high-temperature annealing, the average grain size of the films is greatly reduced, and the grain boundaries enlarge. At the same time, the impurities in the film increase after annealing, thereby changing its optical properties. However, annealing is beneficial to improve the structure of the films, which can increase their hardness and the toughness of their shape. After annealing at $600{ }^{\circ} \mathrm{C}$ (deposited at $200^{\circ} \mathrm{C}$ ), the binding energy of each peak of the films shifts toward the direction of structural stability. Studies have shown that the lateral growth of films has a great effect on light transmission. The indirect band gap of the films changes from $0.92 \mathrm{eV}$ to $1.15 \mathrm{eV}$ with the increase in deposition temperature. After annealing, the indirect band gap of the films prepared at $200{ }^{\circ} \mathrm{C}$ decreases. This condition is because of the increase in the grain boundary caused by annealing and the effect of the two exciton peaks on the optical band gap caused by the K-point blue shift of the $\mathrm{MoS}_{2}$ Brillouin zone. The study shows that the surface morphology, crystal structure, and composition of the $\mathrm{MoS}_{2}$ films can be improved by changing the deposition temperature and performing effective annealing. The results can be used to regulate the optical band gap of the films effectively and provide a reference for the application of $\mathrm{MoS}_{2}$ films in semiconductor optoelectronics and smart window films.

Author Contributions: Formal analysis and investigation, B.L. and X.C.; writing-original draft preparation, G.C.; supervision, project administration, and funding acquisition, J.X. All authors have read and agreed to the published version of the manuscript.

Funding: This research was funded by the National Natural Science Foundation of China, grant number 12064006; the Guangxi Natural Science Foundation, grant number 2017GXNSFAA 198121; and the College Student Innovation Project of Guilin University of Technology, grant number 202010596089.

Conflicts of Interest: The authors declare no conflict of interests with regard to the publication of this paper.

\section{References}

1. Scharf, T.W.; Kotula, P.G.; Prasad, S.V. Friction and wear mechanisms in $\mathrm{MoS}_{2} / \mathrm{Sb}_{2} \mathrm{O}_{3} / \mathrm{Au}$ nanocomposite coatings. Acta Mater. 2010, 58, 4100-4109. [CrossRef]

2. Scharf, T.W.; Rajendran, A.M.; Banerjee, R.K.; Sequeda, F. Growth, structure and friction behavior of titanium doped tungsten disulphide (Ti-WS2) nanocomposite thin films. Thin Solid Film. 2009, 517, 5666-5675. [CrossRef] 
3. Ai, K.; Ruan, C.; Shen, M.; Lu, L. $\mathrm{MoS}_{2}$ Nanosheets with Widened Interlayer Spacing for High-Efficiency Removal of Mercury in Aquatic Systems. Adv. Funct. Mater. 2016, 26, 5542-5549. [CrossRef]

4. Gonzalez, G.A.; Alvarado, M.; Ramos, M.A.; Berhault, G.; Chianelli, R.R. Transition states energies for catalytic hydrodesulfurization reaction in $\mathrm{Co}_{9} \mathrm{~S}_{8} / \mathrm{MoS}_{2}$ theoretical interface using computer-assisted simulations. Comput. Mater. Sci. 2016, 121, 240-247. [CrossRef]

5. Kaindl, R.; Bayer, B.C.; Resel, R.; Müller, T.; Skakalova, V.; Habler, G.; Abart, R.; Cherevan, A.S.; Eder, D.; Blatter, M.; et al. Growth, structure and stability of sputter-deposited $\mathrm{MoS}_{2}$ thin films. Beilstein J. Nanotechnol. 2017, 8, 1115-1126. [CrossRef]

6. Tyagi, S.; Kumar, A.; Kumar, M.; Singh, B.P. Large area vertical aligned $\mathrm{MoS}_{2}$ layers toward the application of thin film transistor. Mater. Lett. 2019, 250, 64-67. [CrossRef]

7. Singh, H.; Mutyala, K.; Evans, R.D.; Doll, G.L. An investigation of material and tribological properties of $\mathrm{Sb}_{2} \mathrm{O}_{3} / \mathrm{Au}$-doped $\mathrm{MoS}_{2}$ solid lubricant films under sliding and rolling contact in different environments. Surf. Coat. Technol. 2015, 284, 281-289. [CrossRef]

8. Gong, C.; Xiao, J.; Zhu, L.; Qi, M.; Ma, S. Crystal structure and tribological properties of molybdenum disulfide films prepared by magnetron sputtering technology. Curr. Appl. Phys. 2019, 19, 1318-1324. [CrossRef]

9. Wang, J.; Deng, S.; Liu, Z.; Liu, Z. The rare two-dimensional materials with Dirac cones. Natl. Sci. Rev. 2015, 2, 22-39. [CrossRef]

10. Li, Q.; Tang, L.; Zhang, C.; Wang, D.; Chen, Q.-J.; Feng, Y.; Tang, L.; Chen, K.-Q. Seeking the Dirac cones in the $\mathrm{MoS}_{2} /$ WSe2 van der Waals heterostructure. Appl. Phys. Lett. 2017, 111, 171602. [CrossRef]

11. Zhang, Y.; Zhuang, Y.; Liu, L.; Qiu, P.; Su, L.; Teng, X.; Fu, G.; Yu, W. The microstructure evolution during $\mathrm{MoS}_{2}$ films growth and its influence on the $\mathrm{MoS}_{2}$ optical-electrical properties in $\mathrm{MoS}_{2} / \mathrm{p}$-Si heterojunction solar cells. Superlattices Microstruct. 2020, 137, 106352. [CrossRef]

12. Chang, H.Y.; Yang, S.; Lee, J.; Tao, L.; Hwang, W.S.; Jena, D.; Lu, N. Akinwande, High-Performance, Highly Bendable $\mathrm{MoS}_{2}$ Transistors with High-K Dielectrics for Flexible Low-Power Systems. ACS Nano 2013, 7, 5446-5452. [CrossRef] [PubMed]

13. Kim, S.; Konar, A.; Hwang, W.-S.; Lee, J.H.; Lee, J.; Yang, J.; Jung, C.; Kim, H.; Yoo, J.; Choi, J.Y.; et al. High-mobility and low-power thin-film transistors based on multilayer $\mathrm{MoS}_{2}$ crystals. Nat. Commun. 2012, 3, 1011. [CrossRef] [PubMed]

14. Zhang, S.; Li, R.; Yao, Z.; Liao, P.; Li, Y.; Tian, H.; Wang, J.; Liu, P.; Guo, J.; Liu, K.; et al. Laser annealing towards high-performance monolayer $\mathrm{MoS}_{2}$ and WSe2 field effect transistors. Nanotechnology 2020, 31, 30LT02. [CrossRef]

15. Guo, J.; Yang, B.; Zheng, Z.; Jiang, J. Observation of abnormal mobility enhancement in multilayer $\mathrm{MoS}_{2}$ transistor by synergy of ultraviolet illumination and ozone plasma treatment. Phys. E Low-Dimens. Syst. Nanostruct. 2017, 87, 150-154. [CrossRef]

16. Wang, Y.; Ou, J.Z.; Balendhran, S.; Chrimes, A.F.; Mortazavi, M.; Yao, D.D.; Field, M.R.; Latham, K.; Bansal, V.;

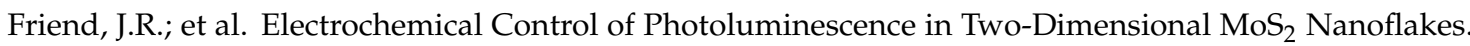
ACS Nano 2013, 7, 10083-10093. [CrossRef]

17. Arzate, N.; Mendoza, B.S.; Nava, R.A.V.A. Optical spin injection in $\mathrm{MoS}_{2}$ monolayers. Phys. Rev. B 2016, 93, 115433. [CrossRef]

18. Ocak, Y.S.; Bozkaplan, C.; Ahmed, H.S.; Tombak, A.; Genisel, M.F.; Asubay, S. Temperature dependent electrical characterization of RF sputtered $\mathrm{MoS}_{2} / \mathrm{n}-\mathrm{Si}$ heterojunction. Optik 2017, 142, 644-650. [CrossRef]

19. Sun, J.; Li, X.; Guo, W.; Zhao, M.; Fan, X.; Dong, Y.; Xu, C.; Deng, J.; Fu, Y. Synthesis Methods of Two-Dimensional $\mathrm{MoS}_{2}$ : A Brief Review. Crystalsvolume 2017, 7, 198. [CrossRef]

20. Sharma, I.; Batra, Y.; Flauraud, V.; Brugger, J.; Mehta, B.R. Growth of Large-Area 2D MoS 2 Arrays at Pre-Defined Locations Using Stencil Mask Lithography. J. Nanosci. Nanotechnol. 2018, 18, 1824-1832. [CrossRef]

21. Kim, D.; Jo, Y.; Jung, D.H.; Lee, J.S.; Kim, T. Electrical and Optical Characteristics of Two-Dimensional $\mathrm{MoS}_{2}$ Film Grown by Metal-Organic Chemical Vapor Deposition. J. Nanosci. Nanotechnol. 2020, 20, 3563-3567. [CrossRef] [PubMed]

22. Fan, R.; Mao, J.; Yin, Z.; Jie, J.; Dong, W.; Fang, L.; Zheng, F.; Shen, M. Efficient and Stable Silicon Photocathodes Coated with a Vertically Standing Nano-MoS 2 Films for Solar Hydrogen Production. ACS Appl. Mater. Interfaces 2017, 9, 6123-6129. [CrossRef] [PubMed] 
23. Hussain, S.; Shehzad, M.A.; Vikraman, D.; Khan, M.F.; Singh, J.; Choi, D.-C.; Seo, Y.; Eom, J.; Lee, W.-G.; Jung, J. Synthesis and characterization of large-area and continuous $\mathrm{MoS}_{2}$ atomic layers by RF magnetron sputtering. Nanoscale 2016, 8, 4340-4347. [CrossRef] [PubMed]

24. Yu, Y.; Ji, Z.; Zu, S.; Du, B.; Kang, Y.; Li, Z.; Zhou, Z.; Shi, K.; Fang, Z. Ultrafast Plasmonic Hot Electron Transfer in Au Nanoantenna/MoS ${ }_{2}$ Heterostructures. Adv. Funct. Mater. 2016, 26, 6394-6401. [CrossRef]

25. López, D.E.; Niu, Y.; Yin, J.; Cooke, K.; Rees, N.V.; Palmer, R.E. Enhancement of the Hydrogen Evolution Reaction from Ni-MoS 2 Hybrid Nanoclusters. ACS Catal. 2016, 6, 6008-6017. [CrossRef]

26. Tao, J.; Chai, J.; Lu, X.; Wong, L.M.; Wong, T.I.; Pan, J.; Xiong, Q.; Chi, D.; Wang, S. Growth of wafer-scale $\mathrm{MoS}_{2}$ monolayer by magnetron sputtering. Nanoscale 2015, 7, 2497-2503. [CrossRef]

27. Wang, L.; Jie, J.; Shao, Z.; Zhang, Q.; Zhang, X.; Wang, Y.; Sun, Z.; Lee, S.-T. MoS $2 /$ Si Heterojunction with Vertically Standing Layered Structure for Ultrafast, High-Detectivity, Self-Driven Visible-Near Infrared Photodetectors. Adv. Funct. Mater. 2015, 25, 2910-2919. [CrossRef]

28. Schultz, D.M.; Yoon, T.P. Solar Synthesis: Prospects in Visible Light Photocatalysis. Science 2014, 343, 1239176. [CrossRef]

29. Ding, S.-S.; Huang, W.-Q.; Yang, Y.-C.; Zhou, B.-X.; Hu, W.-Y.; Long, M.; Peng, P.; Huang, G.-F. Dual role of monolayer $\mathrm{MoS}_{2}$ in enhanced photocatalytic performance of hybrid $\mathrm{MoS}_{2} / \mathrm{SnO}_{2}$ nanocomposite. J. Appl. Phys. 2016, 119, 205704. [CrossRef]

30. Li, X.; Li, X.; Zang, X.; Zhu, M.; He, Y.; Wang, K.; Xie, D.; Zhu, H. Role of hydrogen in the chemical vapor deposition growth of $\mathrm{MoS}_{2}$ atomic layers. Nanoscale 2015, 7, 8398-8404. [CrossRef]

31. Qi, M.; Xiao, J.; Gong, C. Thermal annealing effects on the electrophysical characteristics of sputtered $\mathrm{MoS}_{2}$ thin films by Hall effect measurements. Semicond. Sci. Technol. 2019, 34, 045017. [CrossRef]

32. Jiang, J.; Zheng, Z.; Guo, J. Tuning the hysteresis voltage in $2 \mathrm{D}$ multilayer $\mathrm{MoS}_{2}$ FETs. Phys. B Condens. Matter 2016, 498, 76-81. [CrossRef]

33. Ren, X.; Qi, X.; Shen, Y.; Xiao, S.; Xu, G.; Zhang, Z.; Huang, Z.; Zhong, J. 2D co-catalytic MoS 2 nanosheets embedded with $1 \mathrm{D} \mathrm{TiO}_{2}$ nanoparticles for enhancing photocatalytic activity. J. Phys. D Appl. Phys. 2016, 49, 315304. [CrossRef]

34. Zhang, X.; Zhang, Y.; Yu, B.-B.; Yin, X.-L.; Jiang, W.-J.; Jiang, Y.; Hu, J.-S.; Wan, L.-J. Physical vapor deposition of amorphous $\mathrm{MoS}_{2}$ nanosheet arrays on carbon cloth for highly reproducible large-area electrocatalysts for the hydrogen evolution reaction. J. Mater. Chem. A 2015, 3, 19277-19281. [CrossRef]

35. Zhou, L.; Xia, T.; Cao, T.; Wang, L.; Chen, Y.; Li, S.; Wang, R.; Guo, H. Morphology/phase-dependent MoS $_{2}$ nanostructures for high-efficiency electrochemical activity. J. Alloys Compd. 2020, 818, 152909. [CrossRef]

36. Kim, H.-S.; Kumar, M.M.D.; Kim, J.; Lim, D. Vertical growth of $\mathrm{MoS}_{2}$ layers by sputtering method for efficient photoelectric application. Sens. Actuators A Phys. 2018, 269, 355-362. [CrossRef]

37. Hao, S.; Gao, Y.; Yang, B. Controllable growth and electrostatic properties of Bernal stacked bilayer MoS 2 . J. Appl. Phys. 2016, 120, 124310. [CrossRef]

38. Li, Z.; Jiang, S.; Huo, Y.; Liu, M.; Yang, C.; Zhang, C.; Liu, X.; Sheng, Y.; Li, C.; Man, B. Controlled-layer and large-area $\mathrm{MoS}_{2}$ films encapsulated Au nanoparticle hybrids for SERS. Opt. Express 2016, 24, 26097-26108. [CrossRef]

39. Murugesan, D.; Prakash, S.; Ponpandian, N.; Manisankar, P.; Viswanathan, C. Two dimensional $\alpha-\mathrm{MoO}_{3}$ nanosheets decorated carbon cloth electrodes for high-performance supercapacitors. Colloids Surf. A Physicochem. Eng. Asp. 2019, 569, 137-144. [CrossRef]

40. Kite, S.V.; Chate, P.A.; Garadkar, K.M.; Sathe, D.J. Effect of annealing temperature on properties of molybdenum disulfide thin films. J. Mater. Sci. Mater. Electron. 2017, 28, 16148-16154. [CrossRef]

41. Hossain, A.; Merzougui, B.A.; Alharbi, F.H.; Tabet, N. Electrochemical deposition of bulk $\mathrm{MoS}_{2}$ thin films for photovoltaic applications. Sol. Energy Mater. Sol. Cells 2018, 186, 165-174. [CrossRef]

42. Eda, G.; Yamaguchi, H.; Voiry, D.; Fujita, T.; Chen, M.; Chhowalla, M. Photoluminescence from Chemically Exfoliated $\mathrm{MoS}_{2}$. Nano Lett. 2011, 11, 5111-5116. [CrossRef] [PubMed]

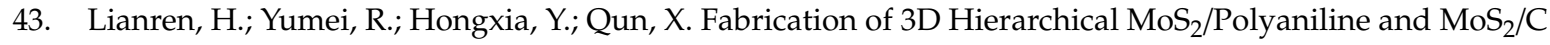
Architectures for Lithium-Ion Battery Applications. ACS Appl. Mater. Interfaces 2014, 6, 14644-14652.

44. Heo, S.N.; Ishiguro, Y.; Hayakawa, R.; Chikyow, T.; Wakayama, Y. Perspective: Highly ordered $\mathrm{MoS}_{2}$ thin films grown by multi-step chemical vapor deposition process. APL Mater. 2016, 4, 030901. [CrossRef] 
45. Shimizu, J.; Ohashi, T.; Matsuura, K.; Muneta, I.; Kakushima, K.; Tsutsui, K.; Wakabayashi, H. High-mobility and low-carrier-density sputtered $\mathrm{MoS}_{2}$ film formed by introducing residual sulfur during low-temperature in 3\%-H2annealing for three-dimensional ICs. Jpn. J. Appl. Phys. 2017, 56, 04CP06. [CrossRef]

46. Hao, S.; Yang, B.; Yuan, J.; Gao, Y. Substrate induced anomalous electrostatic and photoluminescence propeties of monolayer $\mathrm{MoS}_{2}$ edges. Solid State Commun. 2017, 249, 1-6. [CrossRef]

47. Singh, R.; Shweta, T. Structural and optical properties of few-layer $\mathrm{MoS}_{2}$ thin films grown on various substrates using RF sputtering process. J. Mater. Sci. Mater. Electron. 2019, 30, 7665-7680. [CrossRef]

48. Benavente, E.; Ana, M.A.S.; Mendiza'bal, F.; Gonza'lez, G. Intercalation chemistry of molybdenum disulfide. Coord. Chem. Rev. 2002, 224, 87-109. [CrossRef]

49. Coulter, J.; Birnie, D.P. Assessing Tauc Plot Slope Quantification: ZnO Thin Films as a Model System. Phys. Status Solidi 2018, 255, 1700393. [CrossRef]

50. Xiao, J.; Qi, M.; Cheng, Y.; Jiang, A.; Zeng, Y.; Ma, J. Influences of nitrogen partial pressure on the optical properties of copper nitride films. RSC Adv. 2016, 6, 40895-40899. [CrossRef]

Publisher's Note: MDPI stays neutral with regard to jurisdictional claims in published maps and institutional affiliations.

(C) 2020 by the authors. Licensee MDPI, Basel, Switzerland. This article is an open access article distributed under the terms and conditions of the Creative Commons Attribution (CC BY) license (http://creativecommons.org/licenses/by/4.0/). 